\title{
Color Formation Mechanism of Ceramic Pigments Synthesized in the $\mathrm{TiO}_{2}-\mathrm{SnO}-\mathrm{ZnO}$ Compounds
}

\author{
Soomin Kim, Ungsoo Kim ${ }^{\dagger}$, and Woo-Seok Cho \\ Ceramicware Center, Korea Institute of Ceramic Engineering and Technology, Icheon 17303, Korea \\ (Received April 16, 2018; Revised June 26, 2018; Accepted June 27, 2018)
}

\begin{abstract}
This study deals with the color formation of ceramic pigment in the $\mathrm{TiO}_{2}-\mathrm{SnO}-\mathrm{ZnO}$ system. We designed compounds to control the color formation depending on the composition using the Design of Experiment. The color coordinate values of synthesized pigments, $L^{*} a^{*} b^{*}$ were measured and statistically analyzed color for changing elements depending on its composition. The relationship between the major crystalline phases and chromaticity was examined using XRD, and the oxidation states of each element were analyzed by XPS. The synthesized pigments based on the compound design exhibited various color changes ranging from yellow-orange to green-blue and brown. The statistical analysis on the spectrophotometer results shows that $a^{*}$ and $b^{*}$ values decreased with $\mathrm{TiO}_{2}$ content, and increased with $\mathrm{SnO}$ content. Yellow-orange color was detected with the main peak of $\mathrm{SnO}$, and the green-blue color developed with the main peak of $\mathrm{Zn}_{2} \mathrm{TiO}_{4}$. The $\mathrm{a}^{*}$ and $\mathrm{b}^{*}$ values increased with increased $\mathrm{SnO}$ peak intensity, and decreased with increased $\mathrm{Zn}_{2} \mathrm{TiO}_{4}$ peak intensity. The results revealed that pigment color formation was influenced by changes in the main crystalline phases and crystalline intensity. However, XPS analysis of the oxidation states of each element showed little correlation with the pigment chromaticity result.
\end{abstract}

Key words : Inorganic pigment, Solid-state reaction, Raw material, Design of Experiment, Color

\section{Introduction}

$\mathbf{I}_{\mathrm{m}}^{\mathrm{n}}$ norganic pigments, which are manufactured mainly from metallic compounds, have higher chemical and physical stability than organic pigments against UV light, polluted materials, and the surrounding environment. In particular, inorganic pigments show stable color development at high temperatures between $500^{\circ} \mathrm{C}$ and $1000^{\circ} \mathrm{C}$, and provide light resistance against the UV (resistance against degradation due to oxidation driven by light energy), moisture resistance, and durability. Moreover, with their relatively low production costs, they are widely used in various applications such as paints, varnishes, inks, ceramics, and glasses. However, inorganic pigments provide less vivid color and tint strength than organic pigments, and have a relatively narrow range of color formation. Even worse, it is difficult to control color formation owing to limited composition. ${ }^{1-4)}$

Currently, there is a strong interest in a wide variety of colors which the product has in various industrial sectors. Color trends have been released in various themes every year, which reveal that different colors are required. The color trends in 2014 and 2016 announced by Korea Color \& Fashion Trend Center include natural and light colors like frost, pale lime yellow, and whispering blue as well as comfortable ones like illusion blue, egret, icicle, sandstorm, and

\footnotetext{
${ }^{\dagger}$ Corresponding author: Ungsoo Kim

E-mail : ukim@kicet.re.kr

Tel : +82-31-645-1422 Fax : +82-31-645-1485
}

shitake. [http://www.cft.or.kr/] Natural colors that can be harmonized with existing strong colors are in demand.

Mass produced inorganic pigments contain heavy metals such as cadmium (Cd), lead ( $\mathrm{Pb}$ ), antimony (Sb) and chromium (Cr). ${ }^{5,6)}$ In particular, colors such as red, pink, and orange contain toxic or polluting substances of Cr-Sn-Ca-Si, $\mathrm{Pb}-\mathrm{Sb}-\mathrm{Sn}-\mathrm{Fe}$, and $\mathrm{Mn}-\mathrm{Al}$ categories but have very limited alternatives in the composition for color formation. ${ }^{7}$ Most metal ions are non-toxic owing to their very low solubility in solvents, but the abovementioned heavy metals are ultimately harmful to humans and could affect the environment. ${ }^{8)}$ To avoid the use of these heavy metals, a number of rules and regulations have laid out in accordance with the roadmap all over the world. According to the Registration, Evaluation, Authorization, and Restriction of Chemicals $(\mathrm{REACH}), \mathrm{EU}$ manufacturers and importers are required to register all chemicals (products containing compounds and chemical compounds) weighing more than 1 ton in EU states, and the regulations on heavy metals are getting stricter and tighter. [http://ec.europa.eu/environment/]

This paper aims to synthesize the pigment in the $\mathrm{TiO}_{2}-$ $\mathrm{SnO}-\mathrm{ZnO}$ system and investigate the color formation mechanism depending on the composition. We demonstrate that various colors can be formed by the mixing ratio of raw materials based on the Design of Experiment, and attempt to analyze and control the color tendency of all the colors. The pigment was synthesized through the solid-state reaction and the heat treatment process was performed under reducing atmosphere with LPG. ${ }^{9)}$ Then, the color formation, 
crystalline phase, and oxidation state of pigments were compared and analyzed to determine the color mechanism based on the composition.

\section{Experiment Procedure}

This study analyzes the cause of color formation and change in inorganic pigments depending on the compositional variation of the $\mathrm{TiO}_{2}-\mathrm{SnO}-\mathrm{ZnO}$ system. We conducted mixture design using the statistical program (Minitab) by setting the range of the main components. Fig. 1 shows the drawing of the simplex (linear design with more than two variables) designed by the Design of Experiment. The single total for three components was set to $4 \mathrm{~mol}$, and 13 compositions were designed with upper and lower limits between 2.5 and $1.5 \mathrm{~mol}, 1.5$ and $0.5 \mathrm{~mol}$, and 1.5 and 0.5 mol for $\mathrm{TiO}_{2}, \mathrm{SnO}$, and $\mathrm{ZnO}$, respectively.

Titanium oxide $\left(\mathrm{TiO}_{2}, 98 \%\right.$, DAEJUNG CHEM), tin oxide
(SnO, 97\%, JUNSEI), and zinc oxide (ZnO, 98\%, DAEJUNG CHEM) were used as starting materials. These materials were mixed with de-ionized water at $1: 1$ ratio in weight at $150 \mathrm{rpm}$ for $24 \mathrm{~h}$ using the ball mill. The mixed slurry was dried at $100^{\circ} \mathrm{C}$ for $24 \mathrm{~h}$, placed in an alumina crucible, and heat treated with the alumina plate at the top. The heat treatment was performed by increasing the temperature up to $900^{\circ} \mathrm{C}$ at $5^{\circ} \mathrm{C} / \mathrm{min}$ under air atmosphere, supplying the mixed gas (LPG $5 \mathrm{~L} / \mathrm{min}+\operatorname{Air} 0.7 \mathrm{~L} / \mathrm{min}$ ) at $900^{\circ} \mathrm{C}$ for $6 \mathrm{~h}$, and then cooling under reducing atmosphere.

To analyze the chromaticity of 13 synthesized pigments, we measured $L^{*}, a^{*}$, and $b^{*}$ values in the color coordinates of the Commission International de I'Eclairage using the UV-vis spectrophotometer (JASCO, V-770, Japan). The L* represents the brightness ranging from 0 (black) to 100 (white) while $a^{*}$ and $b^{*}$ are the chromaticity coordinates. Here, $a^{*}$ is denoted as red $(+a)$ and green $(-a)$; and $b^{*}$ is denoted as yellow $(+\mathrm{b})$ and blue $(-\mathrm{b}) .^{2,3,10)}$ In this study, $\mathrm{X}-$

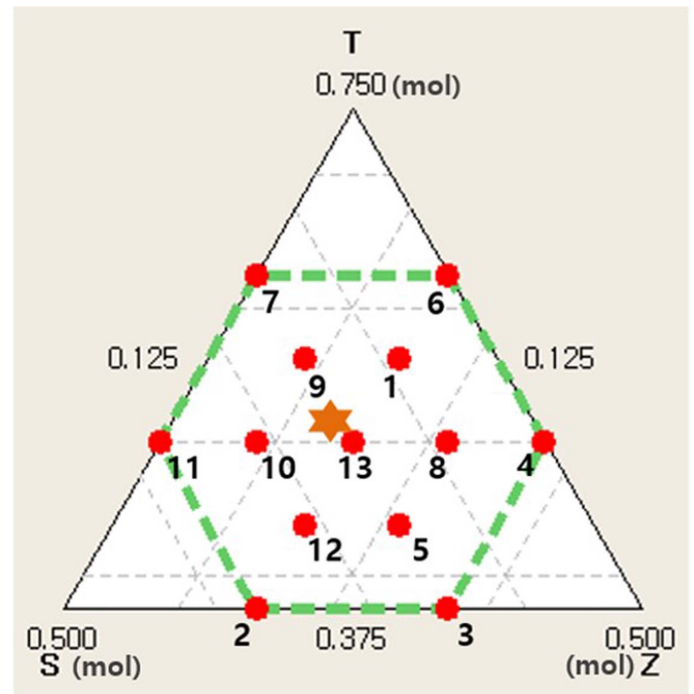

\begin{tabular}{|c|c|c|c|}
\hline RunOrder & $\mathrm{TiO}_{2}$ & $\mathrm{SnO}$ & $\mathrm{ZnO}$ \\
\hline 1 & 2.25 & 0.75 & 1 \\
\hline 2 & 1.5 & 1.5 & 1 \\
\hline 3 & 1.5 & 1 & 1.5 \\
\hline 4 & 2 & 0.5 & 1.5 \\
\hline 5 & 1.75 & 1 & 1.25 \\
\hline 6 & 2.5 & 0.5 & 1 \\
\hline 7 & 2.5 & 1 & 0.5 \\
\hline 8 & 2 & 0.75 & 1.25 \\
\hline 9 & 2.25 & 1 & 0.75 \\
\hline 10 & 2 & 1.25 & 0.75 \\
\hline 11 & 2 & 1.5 & 0.5 \\
\hline 12 & 1.75 & 1.25 & 1 \\
\hline 13 & 2 & 1 & 1 \\
\hline
\end{tabular}

Fig. 1. Mixture design simplex drawing and composition table using the Design of Experiment.
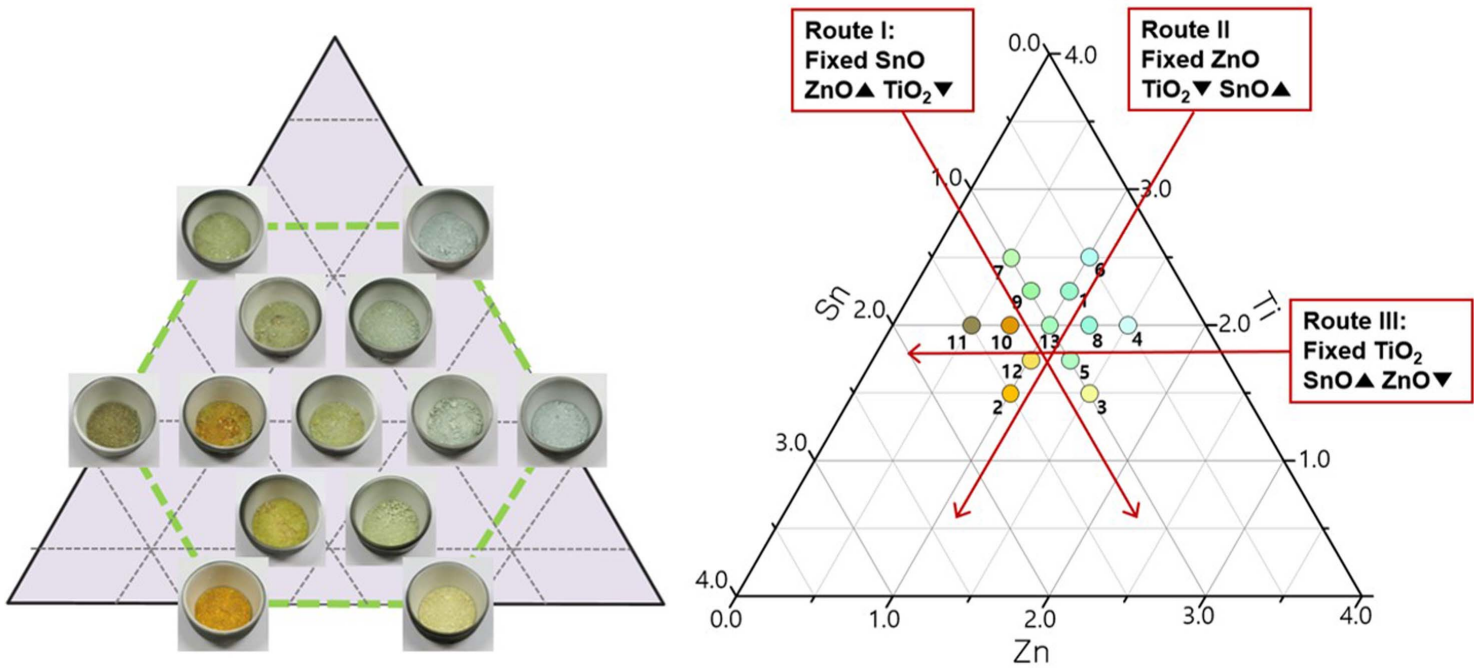

Fig. 2. Thirteen synthesized pigments arranged on the ternary diagram and three route classification. 
ray diffraction (XRD, D/MAX2500VL/PC, Rigaku, Japan) was used to analyze the crystalline phase of pigments. Xray photoelectron spectroscopy (XPS, PHI 5000 versaprobe, ULVAC-PHI Inc., Japan) was used to analyze the oxidation state of Ti, Sn, and Zn elements. The pass energy of the hemispherical energy analyzer was set to $23.5 \mathrm{eV}$ for the analysis of photoelectron energy, and the binding energy of each element was measured in the range between 0 and $1200 \mathrm{eV}$.

\section{Results and Discussion}

The synthesized pigments were arranged on the ternary diagram, as shown in Fig. 2. Various color changes were observed from orange to yellow, green, and blue. To analyze the color change depending on the main components, one component was fixed while the remaining two components were changed in three routes.

For Route I, the addition of $\mathrm{ZnO}$ increased and that of

\section{(a) Route I}

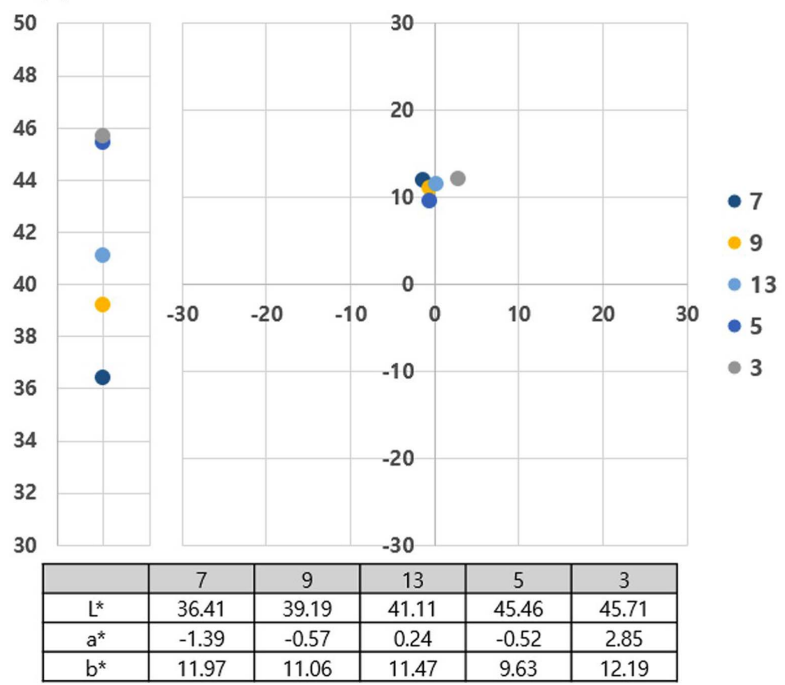

(c) Route III

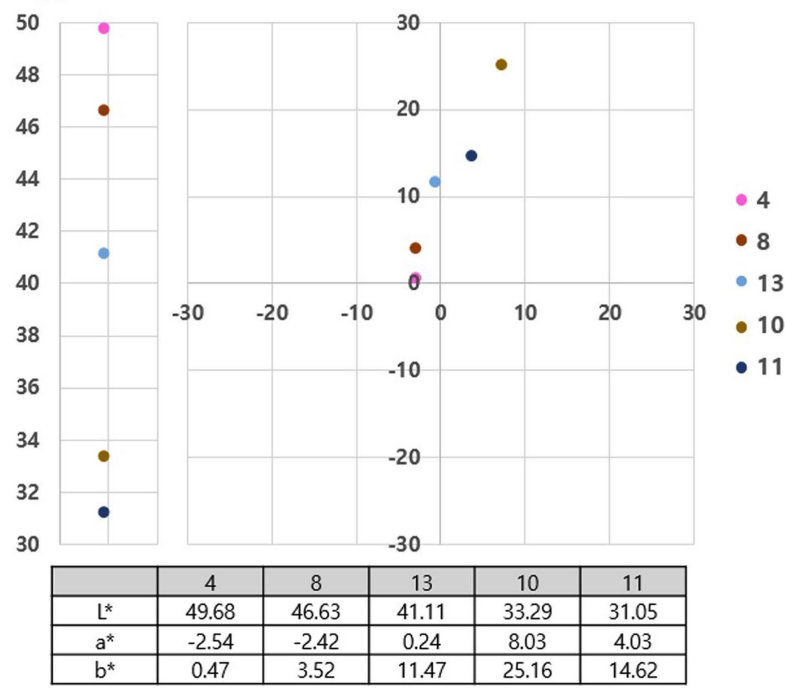

$\mathrm{TiO}_{2}$ decreased with the $\mathrm{SnO}$ fixed to 1 mol. Nos. 7, 9, 13, and 5 mainly showed pale green and No. 3 showed yellow, but they did not show large color fluctuations. For Route II, with $\mathrm{ZnO}$ fixed to $1 \mathrm{~mol}$, various color changes were observed as $\mathrm{TiO}_{2}$ decreased and $\mathrm{SnO}$ increased. The Nos. 6 and 1 compositions which contained high $\mathrm{TiO}_{2}$ showed blue color, but the color changed to green and yellow with the decrease in $\mathrm{TiO}_{2}$ and increase in $\mathrm{SnO}$. Then, the color changed to orange in the No. 2 composition, which contained the highest amount of SnO. For Route III, SnO increased and $\mathrm{ZnO}$ decreased with $\mathrm{TiO}_{2}$ fixed to $2 \mathrm{~mol}$. The color changed from blue to green, and from orange to brown in the Nos. 10 and 11 compositions. The above three routes showed large color fluctuations to orange when the amount of $\mathrm{SnO}$ increased over $1 \mathrm{~mol}$.

Figure 3 shows the pigment colors measured by the spectrophotometer. $\mathrm{L}^{*}$ increased from 36.41 to 45.71 in Route I (Fixed $\mathrm{SnO}: \mathrm{ZnO}$ up, $\mathrm{TiO}_{2}$ down), which suggests that the $\mathrm{ZnO}$ content is the decisive factor affecting the $\mathrm{L}^{*}$ value.

\section{(b) Route II}

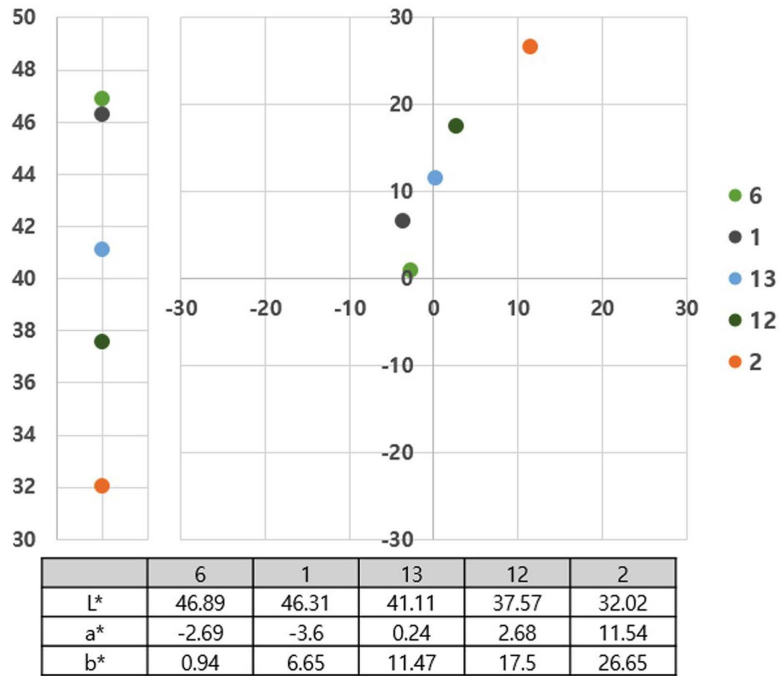

Fig. 3. Spectrophotometric measurement result for each route of 13 pigments. 
The $\mathrm{a}^{*}$ value is nearly 0 , ranging from -1.39 to 2.85 , and the $\mathrm{b}^{*}$ value ranges from 9.63 to 12.19 , showing that its color fluctuation is not large and has only yellow color.

The Route II (Fixed $\mathrm{ZnO}: \mathrm{TiO}_{2} \boldsymbol{\nabla}, \mathrm{SnO} \boldsymbol{\Delta}$ ) shows various color changes. Nos. 6 and 1 pigments have $a^{*}$ values of -2.69 and -3.6 , respectively, and their color is blue. Meanwhile, No. 12 pigment shows gradual decrease in $\mathrm{TiO}_{2}$ and increase in $\mathrm{SnO}$, and has the color yellow with $\mathrm{a}^{*}$ value of 2.68 and $b^{*}$ value of 17.5 . No. 2 pigment, which contains a high ratio of $\mathrm{SnO}$, has $\mathrm{a}^{*}$ and $\mathrm{b}^{*}$ values of 11.54 and 26.65, respectively. It was also observed that the orange pigment was synthesized.

In Route III (Fixed $\mathrm{TiO}_{2}$ : $\mathrm{SnO}$ up, $\mathrm{ZnO}$ down), Nos. 4 and 8 have $\mathrm{a}^{*}$ values of -2.54 and -2.42 , respectively, showing the color blue. No. 10, where the amount of $\mathrm{SnO}$ increased to $1.25 \mathrm{~mol}$, shows the color orange with $\mathrm{a}^{*}$ value of 8.03 and $\mathrm{b}^{*}$ value of 25.16 . No. 11 pigment, which contains the highest ratio of $\mathrm{SnO}$ of $1.5 \mathrm{~mol}$ and lowest $\mathrm{ZnO}$ of $0.5 \mathrm{~mol}$, has a* value of 4.03 and $b^{*}$ value of 14.62 , showing color changes to brown. The observation of the $L^{*}$ value in Routes II and III shows that the $\mathrm{L}^{*}$ value fell sharply from the late 40 s to the early 30 s with the increase in $\mathrm{SnO}$ content.

Figure 4 shows the main effect plot between the composition and the chromaticity analyzed by the statistical program. The larger the graph slope, the greater the effect on the chromaticity. The main effect plot of $\mathrm{L}^{*}$ shows large fluctuations in $\mathrm{SnO}$ and $\mathrm{ZnO}$, and the effects of two ele- ments are inversely proportional to each other. As the content of $\mathrm{SnO}$ increases, the $\mathrm{L}^{*}$ value decreases sharply; as the content of $\mathrm{ZnO}$ increases, the $\mathrm{L}^{*}$ value increases greatly. Meanwhile, $\mathrm{TiO}_{2}$ does not show any significant change in slope, suggesting that $\mathrm{TiO}_{2}$ has little effect on $\mathrm{L}^{*}$.

The main effect plot of $\mathrm{a}^{*}$ shows large fluctuations in $\mathrm{TiO}_{2}$ and $\mathrm{SnO}$. As $\mathrm{TiO}_{2}$ increases, the $\mathrm{a}^{*}$ value decreases and becomes a negative value, which means that the green color appears with increased $\mathrm{TiO}_{2}$ content. Also, as the content of $\mathrm{SnO}$ increases, the $\mathrm{a}^{*}$ value shows a positive value, which means that the red color appears with decreased $\mathrm{TiO}_{2}$ and increased $\mathrm{SnO}$ contents. It was confirmed that $\mathrm{ZnO}$ has less effect on the $a^{*}$ value than other components.

The main effect plot of $b^{*}$ shows that as the content of $\mathrm{TiO}_{2}$ increases, the $\mathrm{b}^{*}$ value decreases; as the content of $\mathrm{SnO}$ increases, the $\mathrm{b}^{*}$ value increases. It may be said that $\mathrm{SnO}$ has the greatest effect on the main effect plot of $b^{*}$ because the $\mathrm{SnO}$ shows relatively large fluctuation compared with other components in the plot.

Figure 5 shows the crystalline phase analysis of pigments classified by each route. The results of Route I (Fixed SnO: $\mathrm{ZnO}$ up, $\mathrm{TiO}_{2}$ down) showed the existence of $\mathrm{TiO}_{2}$ (Rutile), $\mathrm{Zn}_{2} \mathrm{TiO}_{4}, \mathrm{SnO}_{2}$ (Cassiterite), and $\mathrm{SnO}$. The result revealed that the peaks of $\mathrm{Zn}_{2} \mathrm{TiO}_{4}$, and $\mathrm{SnO}$ increased as $\mathrm{ZnO}$ increased and $\mathrm{TiO}_{2}$ decreased, and the peak intensity of $\mathrm{TiO}_{2}$ and $\mathrm{SnO}_{2}$ gradually decreased. The main peak gradually changed from $\mathrm{TiO}_{2}$ and $\mathrm{SnO}_{2}$ to $\mathrm{Zn}_{2} \mathrm{TiO}_{4}$.
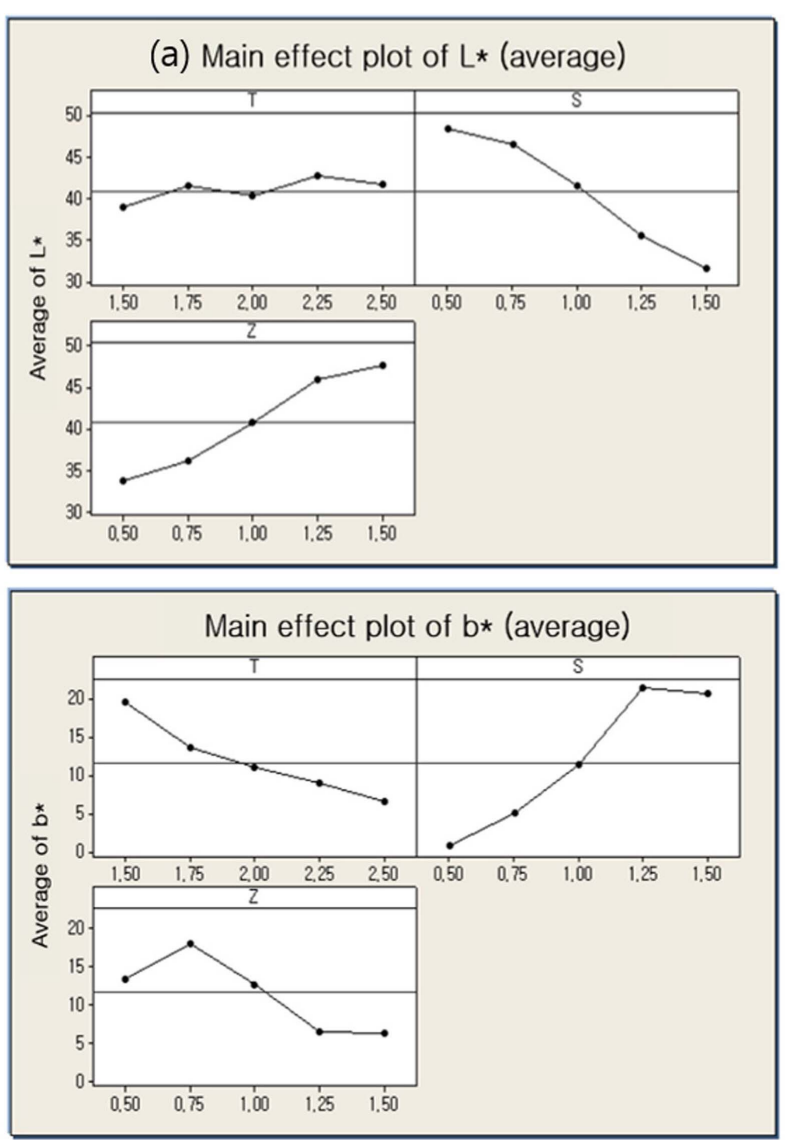

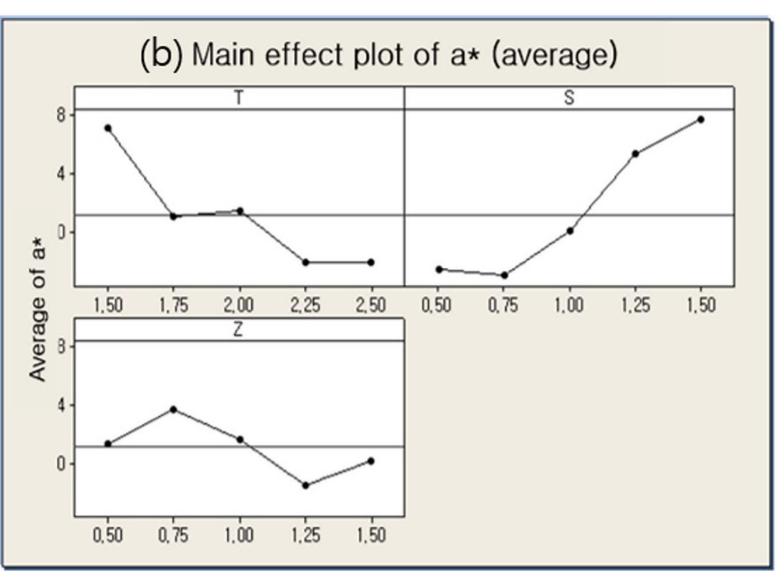

Fig. 4. Main effect plots representing the correlation between the composition of pigments and chromaticity result with Minitab (color comparison according to composition). 
(a) Route I

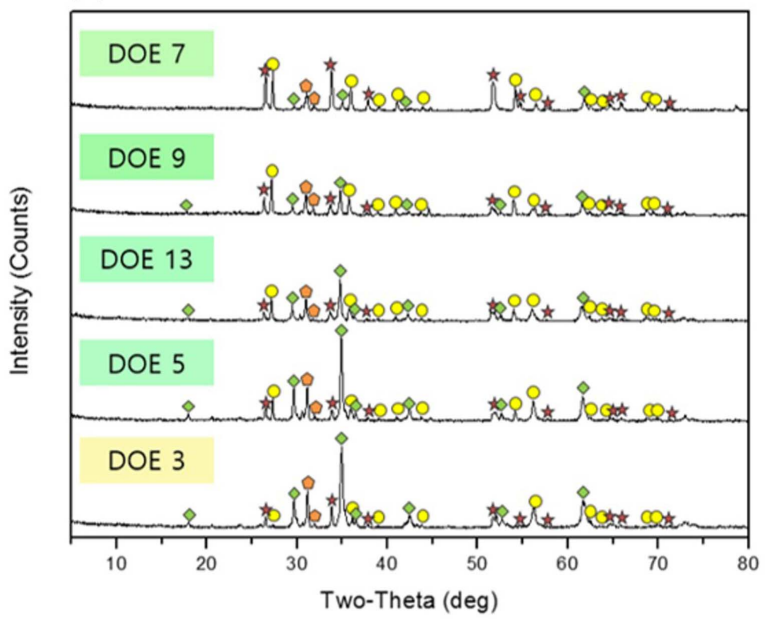

(c) Route III

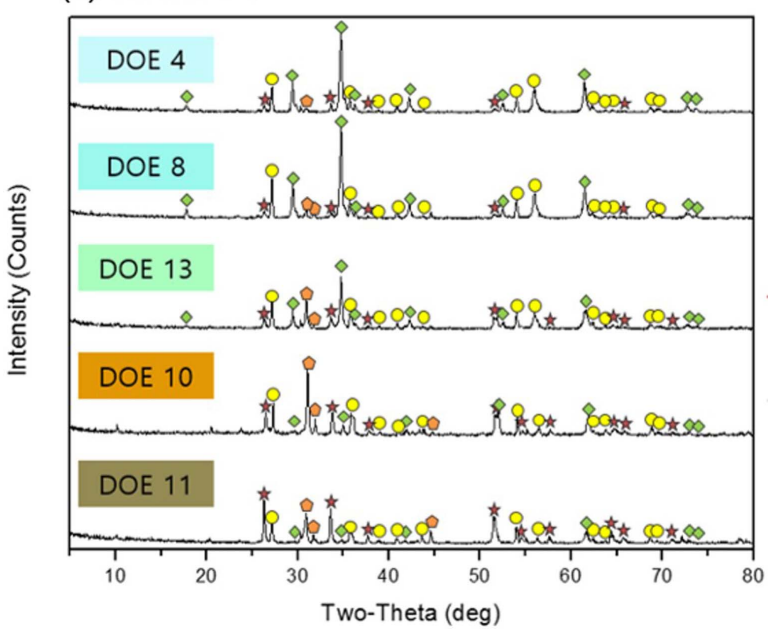

The XRD results in Route II (Fixed $\mathrm{ZnO}$ : $\mathrm{TiO}_{2}$ down, $\mathrm{SnO}$ up) showed that $\mathrm{Zn}_{2} \mathrm{TiO}_{4}$ and $\mathrm{TiO}_{2}$ were the main peaks but their intensity gradually decreased and the intensities of $\mathrm{SnO}_{2}$ and $\mathrm{SnO}$ increased. The main peak of Nos. 12 and 2 pigments, which are colors yellow and orange, was $\mathrm{SnO}$.

In Route III (Fixed $\mathrm{TiO}_{2}$ : $\mathrm{SnO}$ up, $\mathrm{ZnO}$ down), the $\mathrm{Zn}_{2} \mathrm{TiO}_{4}$

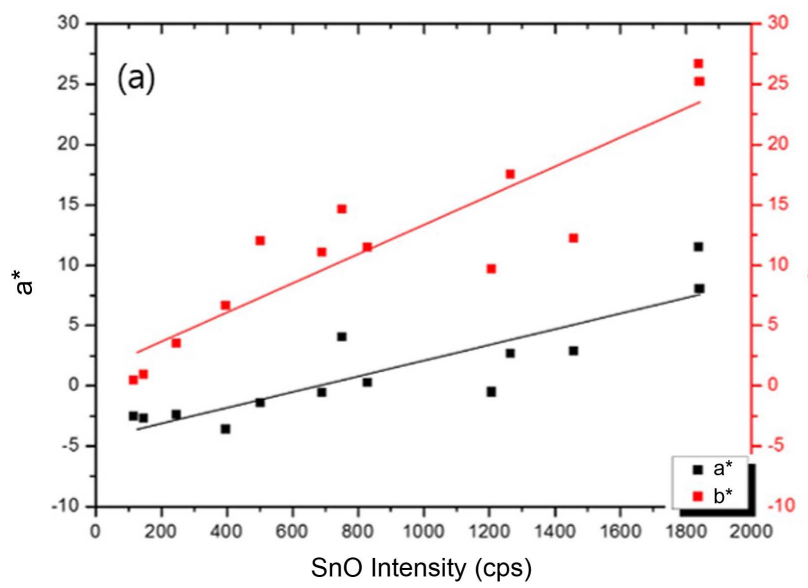

(b) Route II

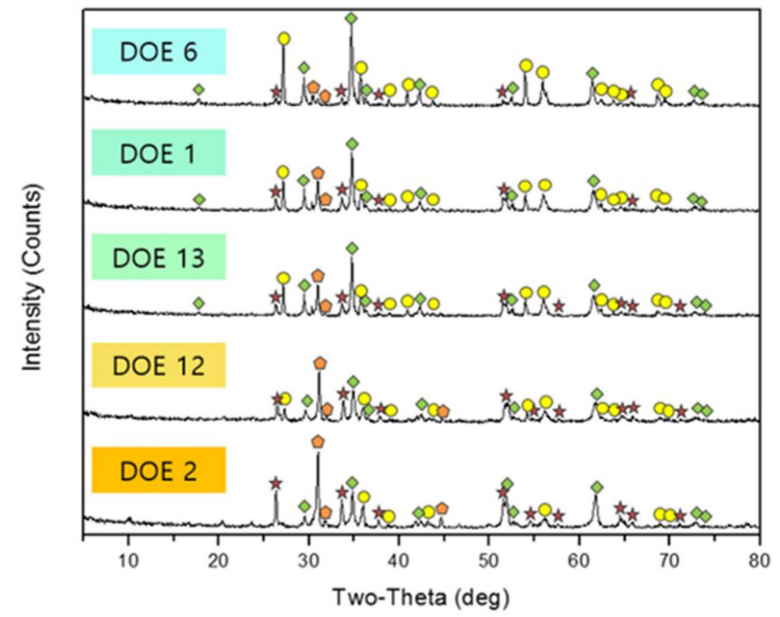

$0: \mathrm{TiO}_{2}$ (Rutile)

$\diamond: \mathrm{Zn}_{2} \mathrm{TiO}_{4}$

$\star: \mathrm{SnO}_{2}$ (Cassiterite)

: : $\mathrm{SnO}$

Fig. 5. XRD crystal phase analysis of each route of 13 pigments synthesized.

peak decreases but the peak intensities of $\mathrm{SnO}_{2}$ and $\mathrm{SnO}$ increased. $\mathrm{SnO}$ appears as the main peak as the addition of $\mathrm{SnO}$ increases. The No. 11 pigment, which has the main peak at $\mathrm{SnO}_{2}$, shows the color brown. This means that the yellow-orange color appears when the $\mathrm{SnO}$ is the main peak as in the second route, and the green-blue appears at the

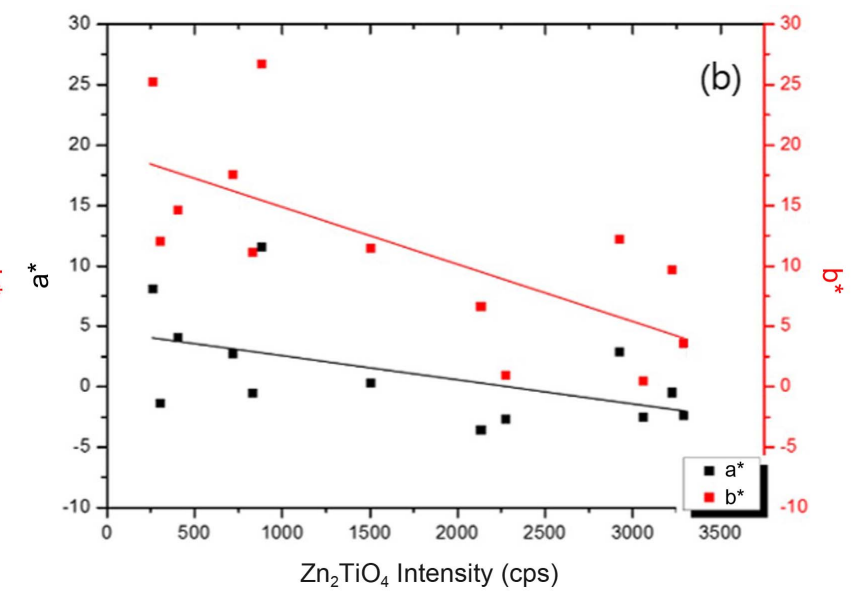

Fig. 6. Correlation between the peak intensity and pigment chromaticity of $\mathrm{SnO}$ and $\mathrm{Zn}_{2} \mathrm{TiO}_{4}$ crystalline phase. 


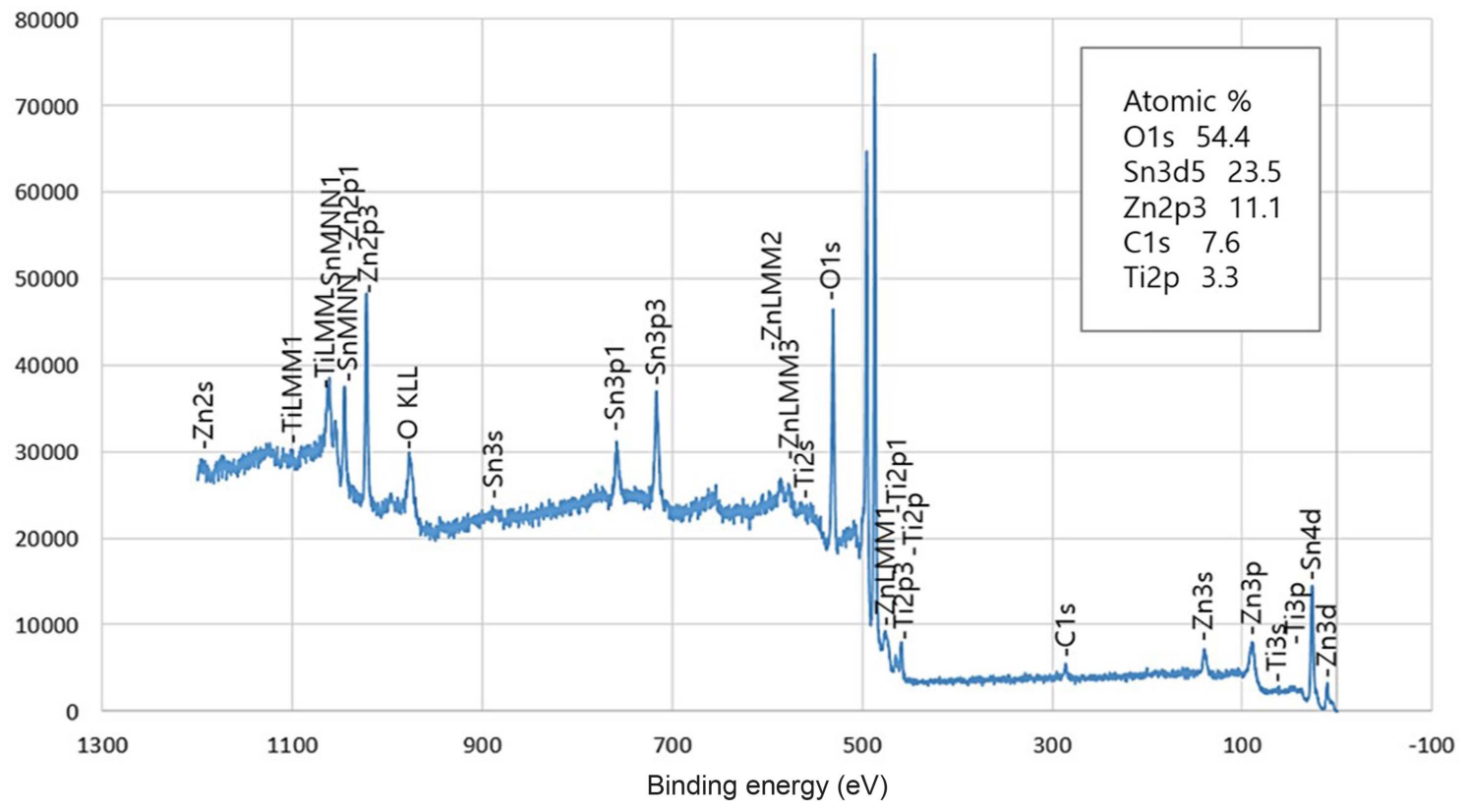

\begin{tabular}{|c|c|c|c|c|}
\hline Pass energy & Step & Time & Scan & Range \\
\hline $23.5 \mathrm{eV}$ & $0.05 \mathrm{eV}$ & $30 \mathrm{~ms}$ & 15 & $0 \sim 1200 \mathrm{eV}$ \\
\hline
\end{tabular}

Fig. 7. XPS measurement result of No. 1 pigment.

main peak of $\mathrm{Zn}_{2} \mathrm{TiO}_{4}$.

The correlation between the color and crystalline phase shows that the main peak of green-blue pigments is $\mathrm{Zn}_{2} \mathrm{TiO}_{4}$ (Nos. 1, 4, 5, 6, 8, 9, 13). In particular, the main peak of blue color is mainly $\mathrm{TiO}_{2}$ in addition to $\mathrm{Zn}_{2} \mathrm{TiO}_{4}$. The main peak of No.3 pale yellow pigment is $\mathrm{Zn}_{2} \mathrm{TiO}_{4}$, and the second peak is SnO. Pigments Nos. 12, 2, and 10 of yellow-orange color have the main peak at $\mathrm{SnO}$.

Figure 6 shows the change in $\mathrm{a}^{*}$ and $\mathrm{b}^{*}$ values depending on the peak intensity of major crystalline phases identified from XRD analysis. Among the four major phases exhibited in the analysis, the (101) peak of $\mathrm{SnO}$ related to the yelloworange color, and the (311) peak of $\mathrm{Zn}_{2} \mathrm{TiO}_{4}$ related to the

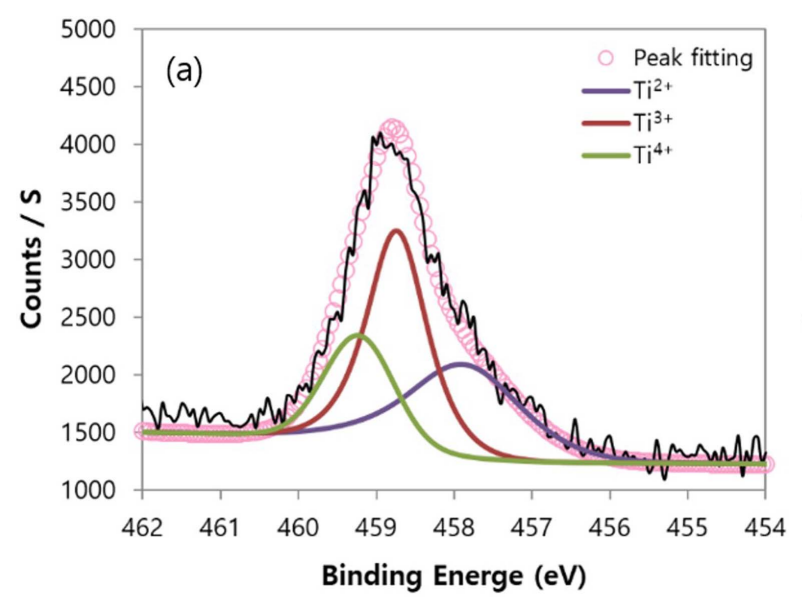

green-blue color were selected for the comparative study.

The correlation between the $\mathrm{SnO}$ peak intensity and chromaticity values $a^{*}$ and $b^{*}$ shows that as the intensity increases, $a^{*}$ and $b^{*}$ values increase. The pigment Nos. 2 and 12 , which exhibited color values of orange, have $\mathrm{SnO}$ intensity of more than 1800 . Meanwhile, the relation between the $\mathrm{Zn}_{2} \mathrm{TiO}_{4}$ peak intensity and chromaticity shows that $a^{*}$ and $b^{*}$ values tend to decrease as the $\mathrm{Zn}_{2} \mathrm{TiO}_{4}$ peak intensity increases. In both cases, the change in $\mathrm{a}^{*}$ is relatively small. The main crystalline phase depends on the contents of each element and this affects color trends.

We analyzed the oxidation state of elements forming 13 pigments through XPS measurement. Fig. 7 shows the XPS

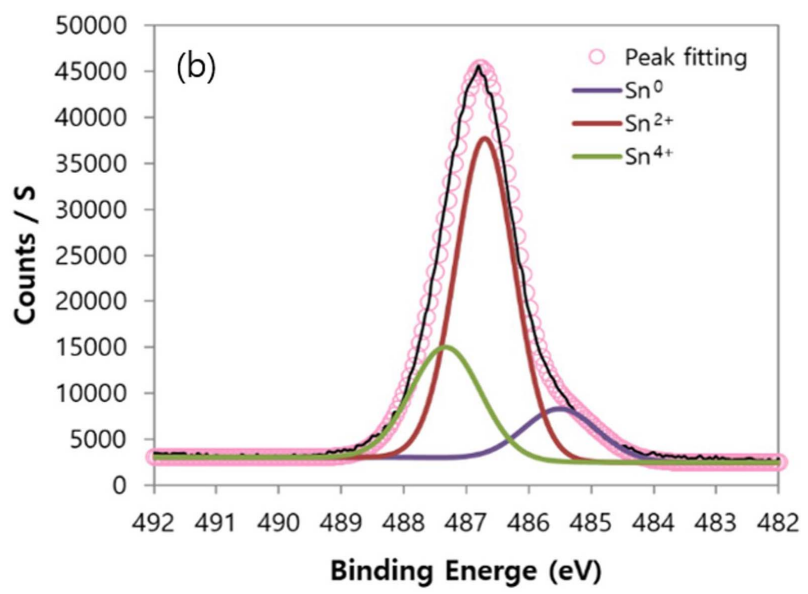

Fig. 8. Analysis on the oxidation state for each element (Ti, Sn) by peak fitting using the XPS measurement result of No. 1 pigment. 

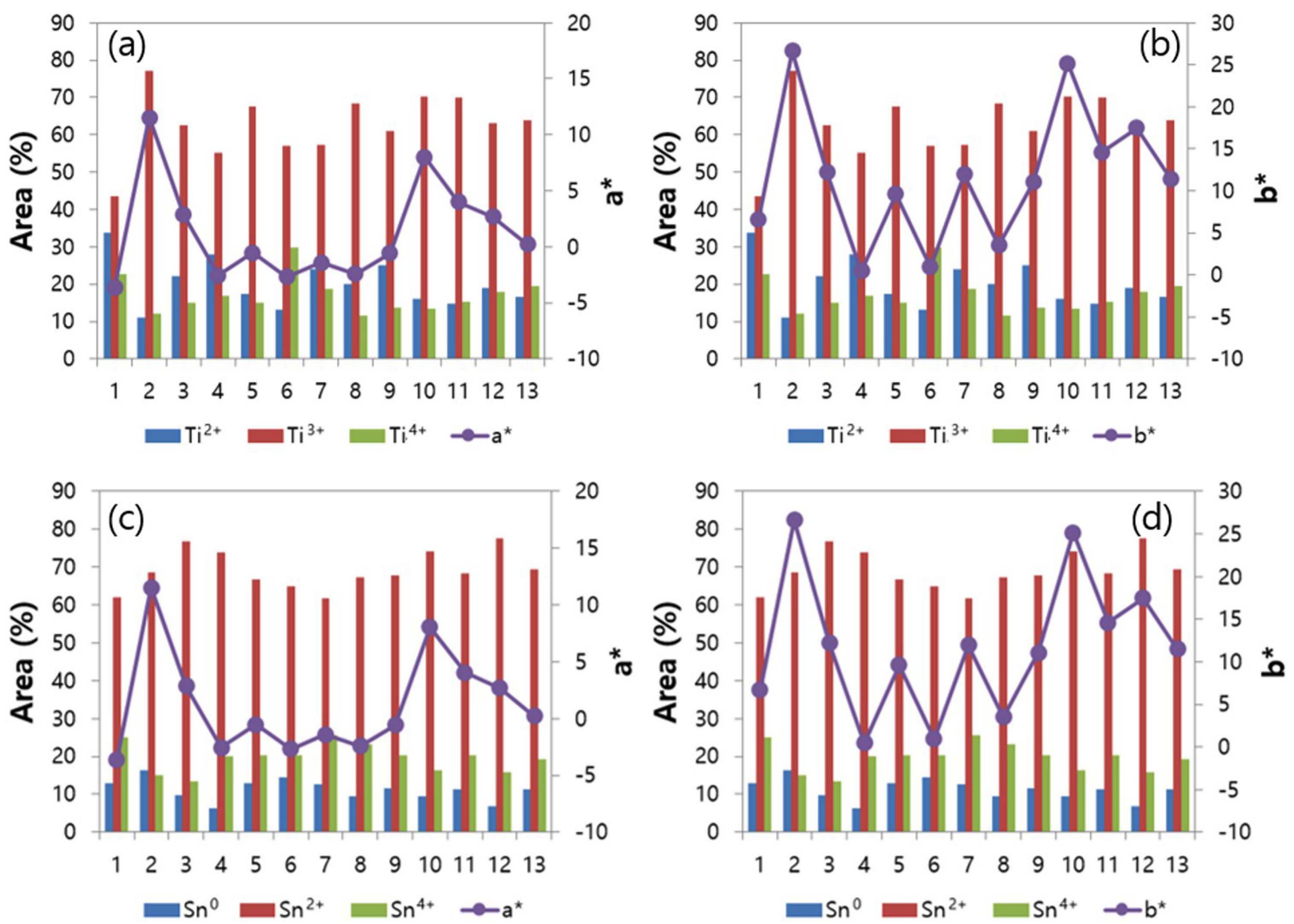

Fig. 9. Comparison of total oxidation state and chromaticity for each element of 13 pigments; (a) Ti and $a^{*}$, (b) Ti and b*, (c) Sn and $\mathrm{a}^{*}$, and (d) Sn and $\mathrm{b}^{*}$.

analysis result for $\mathrm{Ti}, \mathrm{Sn}$, and $\mathrm{Zn}$ elements that existed in pigment No. 1 as an example. We performed the peak fitting for each element using the Shirley method. The peak fitting for each element was calibrated at the carbon peak of $\mathrm{C} 1 \mathrm{~s}$ $284.6 \mathrm{eV}$. Each peak was analyzed at $458.8 \mathrm{eV}$ for Ti2P3/2, $486.8 \mathrm{eV}$ for Sn3d5/2, and $1022.2 \mathrm{eV}$ for $\mathrm{Zn} 2 \mathrm{p} 3 / 2$ referring to existing XPS analysis literature. ${ }^{11-13)}$

The core level spectrum area of Ti, Sn, and $\mathrm{Zn}$ elements was calculated using the Avantage v.4.12 for the quantitative analysis of the oxidation state. Fig. 8 shows the fitting result of pigment No. 1 as an example. Ti was found to exist as three different states of divalence, trivalence, and tetravalence in the range $458.8 \pm 0.4 \mathrm{eV}$ by analyzing Ti2P3/ 2 . The analysis on the $\mathrm{Sn} 3 \mathrm{~d} 5 / 2$ shows that Sn element has a metal state of $\mathrm{Sn}(\mathrm{Sn} 0)$ in the range $485.6 \pm 0.4 \mathrm{eV}$, and has divalence and tetravalence states of $\mathrm{Sn}$ in the range $486.7 \pm$ $0.4 \mathrm{eV}$ and $487.22 \pm 0.4 \mathrm{eV}$, respectively. $\mathrm{Zn}$ was excluded from the analysis because it only exists as a stable divalence state unlike Ti and Sn.

Figure 9 shows how the oxidation state of each element affects the chromaticity $\left(a^{*}, b^{*}\right)$. Fig. 9(a) shows that the change in $\mathrm{a}^{*}$ and $\mathrm{b}^{*}$ is similar to that of $\mathrm{Ti}^{3+}$ portion. As the ratio of $\mathrm{Ti}^{3+}$ increases, $\mathrm{a}^{*}$ and $\mathrm{b}^{*}$ values increase in the positive direction ( $\mathrm{a}^{*}$ : red, $\mathrm{b}^{*}$ : yellow) as a whole; as the ratio of $\mathrm{Ti}^{3+}$ decreases, the values decrease in the negative direction. Fig. 9(b) shows that $a^{*}$ and $b^{*}$ have weak correlation with the oxidation state of Sn. The XPS analysis result indicates that the crystalline phases formed by raw materials and each portion significantly affect the pigment color formation rather than the oxidation state of the element.

\section{Conclusions}

In this study, color development in the $\mathrm{TiO}_{2}-\mathrm{SnO}-\mathrm{ZnO}$ system was investigated using the Design of Experiment. Thirteen compositions were designed for $\mathrm{TiO}_{2}, \mathrm{SnO}$, and $\mathrm{ZnO}$, respectively, and the pigments were synthesized using solid-state reaction. The chromaticity of 13 synthesized pigments exhibited various pastel colors depending on the change in compositions ranging from yellow, orange, and green, blue to brown. It was confirmed that various colors were formed depending on the change in composition.

The analysis of the chromaticity using the statistical program shows that $\mathrm{L}^{*}$ decreases as the content of $\mathrm{SnO}$ increases, but $\mathrm{L}^{*}$ increases as the content of $\mathrm{ZnO}$ increases. It also shows that $\mathrm{a}^{*}$ and $\mathrm{b}^{*}$ decrease as the content of $\mathrm{TiO}_{2}$ increases, but increase as the content of $\mathrm{SnO}$ increases.

These results can be analyzed in relation to the crystalline phase analysis. The compositions which show the main peak at $\mathrm{Zn}_{2} \mathrm{TiO}_{4}$ exhibited color values of green-blue. Meanwhile, the compositions which show the main peak at $\mathrm{SnO}$ exhibited a color value of yellow-orange, and the compositions which show the main peak at $\mathrm{SnO}_{2}$ (Cassiterite) exhibited a color value of brown. The analysis of the correlation 
between the intensities and chromaticity of these main peaks indicates that $a^{*}$ and $b^{*}$ increase as the intensity of $\mathrm{SnO}$ increases, but decrease as the intensity of $\mathrm{Zn}_{2} \mathrm{TiO}_{4}$ increases. The results of these experiments provide basic evidence of the main crystalline phase influencing color trends.

The correlation of the chromaticity with the oxidation state of elements was analyzed using XPS. In general, the change in $\mathrm{a}^{*}$ and $\mathrm{b}^{*}$ values was similar to that of $\mathrm{Ti}^{3+}$ portion. However, no special correlation existed between the chromaticity and oxidation state of Sn. It was confirmed that the color formation of ceramic pigments in the $\mathrm{TiO}_{2}-$ $\mathrm{SnO}-\mathrm{ZnO}$ composition system was strongly influenced by the main crystalline phases rather than the element oxidation state of elements.

\section{REFERENCES}

1. S. Novaconi and N. Vaszilcsin, "Inductive Heating Hydrothermal Synthesis of Titanium Dioxide Nanostructures," Mater. Lett., 95 59-62 (2013).

2. S. H. Kim, Eco-Friendly Fabrication and Characterization of High Performance Yellow Pigment through the Derivative and Crystallization Process (in Korean), pp. 16-42, Pukyong National University, Busan, 2015.

3. B. R. Son, Synthesis and Characteristics of High-Temperature Blue Nano-Sized Inorganic Pigments (in Korean), pp. 7-11, Sungkyunkwan University, Suwon, 2013.

4. S. M. Kim, U. Kim, and W. S. Cho, "Synthesis of the Orange Color Pigment in the System of $\mathrm{TiO}_{2}-\mathrm{SnO}-\mathrm{ZnO}$ by Solid State Reaction," J. Korean Cryst. Growth Cryst. Technol., 26 [5] 181-87 (2016).

5. C. Sandalinas, S. Ruiz-Moreno, A. Lopez-Gil, and J. Miralles, "Experimental Confirmation by Raman Spec- troscopy of a Pb-Sn-Sb Triple Oxide Yellow Pigment in Sixteenth-Century Italian Pottery," J. Raman Spectrosc., 37 [10] 1146-53 (2006).

6. C. Gargori, S. Cerro, R. Calindo, and G. Monros, "In situ Synthesis of Orange Rutile Ceramic Pigments by NonConventional Methods," Ceram. Int., 36 [1] 23-31 (2010).

7. F. Bondioli, A. M. Ferrari, C. Leonelli, and T. Manfredini, "Syntheses of $\mathrm{Fe}_{2} \mathrm{O}_{3}$ /Silica Red Inorganic Inclusion Pigments for Ceramic Applications," Mater. Res. Bull., 33 [5] 723-29 (1998).

8. M. Jansen and H. P. Letschert, "Inorganic Yellow-Red Pigments without Toxic Metals," Nature, 404 980-82 (2000).

9. K. C. Lee, J. W. Yoon, J. H. Kim, K. T. Hwang, and K. S. Han, "Preparation and Characterization of $\mathrm{CoAl}_{2} \mathrm{O}_{4}$ Blue Ceramic Nano Pigments by Attrition Milling," J. Korean Cryst. Growth Cryst. Technol., 23 [5] 255-64 (2013).

10. T. H. Kim, H. J. Hwang, J. H. Kim, K. T. Hwang, and K. S. Han, "Effect of Bi and $\mathrm{Zr}$ Addition on Yellow Colour Properties of Environment-Friendly Ceria-Based Pigments," J. Korean Cryst. Growth Cryst. Technol., 25 [4] 153-59 (2015).

11. A. Fahlman, C. Nordling, G. Johansson, and K. Hamrin, "Charge Transfer in Transition Metal Carbides and Related Compounds Studied by ESCA," J. Phys. Chem. Solids, 30 [7] 1835-47 (1969).

12. D. Borgmann, E. Hums, G. Hopfengartner, G. Wedler, G. W. Spitznagel, and I. Rademacher, "XPS Studies of Oxidic Model Catalysts: Internal Standards and Oxidation Numbers," J. Electron Spectrosc. Relat. Phenom., 63 [2] 91-116 (1993).

13. C. D. Wagner, W. M. Riggs, L. E. Davis, J. F. Moulder, and G. E. Muilenberg, Handbook of X-Ray Photoelectron Spectroscopy; p. 111, Physical Electronics Division, Perkin-Elmer Corporation, Eden Prairie, Minnesota, 1979. 